\title{
Práticas culinárias de mulheres residentes em Cruzeiro do Sul, no Acre:
}

uma abordagem qualitativa e feminista

\section{Culinary practices of women living in Cruzeiro do Sul, Acre:}

a qualitative and feminist approach

\author{
Mayara Sanay da Silva Oliveira ${ }^{1}$ \\ Ramiro Andres Fernandez Unsain 2 \\ Mariana Dimitrov Ulian ${ }^{3}$ \\ Priscila de Morais Sato ${ }^{4}$ \\ Fernanda Baeza Scagliusi ${ }^{5}$
}

A culinária doméstica é uma prática social imbricada em um sistema de gênero que (re) produz ideias de trabalhos diferenciados para homens e mulheres, bem como comportamentos considerados "adequados" para as pessoas. Este trabalho objetiva descrever e discutir o trabalho culinário doméstico realizado por mulheres a partir da perspectiva de performatividade de gênero da filosofa Judith Butler. Trata-se de um estudo qualitativo e feminista. Realizamos entrevistas em profundidade semiestruturadas com 14 mulheres casadas ou que residem com os cônjuges, com idade entre 25 a 41 anos e que cozinhavam em domicílio pelo menos 1 vez por dia; e 05 cônjuges com idade entre 28 a 51 anos. Analisamos os dados com análise de conteúdo, codificamos as entrevistas com especial atenção para os status atribuídos às mulheres e aos homens no núcleo familiar, às diferenças e aos jogos de poderes, aos privilégios que permitem às diferentes pessoas exercerem ou se beneficiarem do poder, às forças e aos processos que emergem dos itens supracitados. Em nossa pesquisa, as mulheres eram as principais responsáveis por realizar os trabalhos culinários domésticos, executando-os sozinhas ou compartilhando com outras figuras femininas. Enquanto seus cônjuges eram praticantes secundários ou terciários da culinária doméstica, realizando essas atividades apenas na ausência de figuras femininas. Todas as mulheres entrevistadas reconheciam a culinária doméstica como uma obrigação social e familiar atribuída à "mãe", à "esposa" e à "dona de casa". Elas realizavam diariamente e continuamente uma série de atividades físicas e cognitivas relacionadas ao trabalho culinário doméstico com intuito de contribuir com a família, cuidar do marido e das crianças, e evitar reclamações ou crítica dos maridos ou outros membros da família. Em relação aos cônjuges, eles identificavam que negar que homens e mulheres deveriam realizar as mesmas atividades domésticas indicaria um pensamento "machista" de sua parte. Contudo, eles afirmavam que os homens deveriam cozinhar apenas quando: morassem sozinhos, não trabalhassem fora de casa, soubessem cozinhar, tivessem "dom" para culinária, gostassem e/ou tivessem o interesse em cozinhar. Dentro de tantas condições e restrições socioculturais para a participação masculina no trabalho culinário doméstico, os maridos e companheiros que realizavam essa atividade em maior frequência se reconheciam como desviantes de uma norma hegemônica por estarem executando uma atividade considerada feminina. Concluímos que as mulheres e os homens disputam ativamente poderes, privilégios, controles e autonomia com intuito de implementar modelos de práticas culinárias que possam performar dentro das suas conjunturas de vidas atuais. 
Palavras-chave: mulheres; culinária; papéis de gênero; feminismo; pesquisa qualitativa.

Keywords: women; culinary; gender roles; feminism; qualitative research.

1 Doutoranda no Programa de Pós-Graduação em Nutrição em Saúde Pública da Faculdade de Saúde Pública da Universidade de São Paulo.

2 Doutor em Ciências pelo Programa de Pós-Graduação Interdisciplinar em Ciências da Saúde da Universidade Federal de São Paulo.

3 Doutora em Ciências pelo Programa de Pós-Graduação em Nutrição em Saúde Pública da Faculdade de Saúde Pública da Universidade de São Paulo.

4 Pós-doutoranda no Programa de Pós-Graduação em Nutrição em Saúde Pública da Faculdade de Saúde Pública da Universidade de São Paulo, doutora em ciências pelo Programa de Pós-Graduação Interdisciplinar em Ciências da Saúde da Universidade Federal de São Paulo.

${ }_{5}$ Professora Doutora no Departamento de Nutrição da Faculdade de Saúde Pública da Universidade de São Paulo. 